\title{
Immunocytochemical Expression of IFN- $\gamma$ and IL-4 in Tuberculous Lymphadenitis with Dark Oval Bodies
}

\author{
Humairah Medina Liza Lubis ${ }^{1 *}$, Ratna Akbari Ganie ${ }^{2}$, Delyuzar Delyuzar ${ }^{3}$, Putri Chairani Eyanoer ${ }^{4}$, Delfitri Munir ${ }^{5}$ \\ ${ }^{1}$ Postgraduate, Doctoral Programme, Faculty of Medicine, Universitas Sumatera Utara, Medan, Indonesia; ${ }^{2}$ Departement of \\ Clinical Pathology, Faculty of Medicine, Universitas Sumatera Utara, General Hospital of H. Adam Malik, Medan, Indonesia; \\ ${ }^{3}$ Departement of Anatomical Pathology, Faculty of Medicine, Universitas Sumatera Utara, Medan, Indonesia; ${ }^{4}$ Departement of \\ Community Medicine, Faculty of Medicine, Universitas Sumatera Utara, Medan, Indonesia; ${ }^{5}$ Department of Otorhinolaryngology, \\ Head and Neck Surgery, Faculty of Medicine, Universitas Sumatera Utara, Medan, Indonesia
}

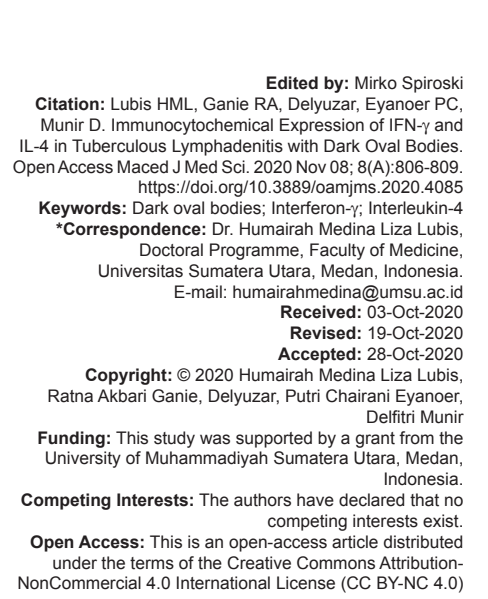

\section{Abstract}

BACKGROUND: We noticed some smears being cytologically diagnosed as common chronic lymphadenitis that cannot be treated with ordinary antibiotics, but succeeded with the anti-tuberculosis drug (ATD), even though it takes longer, up to a year or more. Re-examining the MGG smears, we got cases that show the structure, we call Dark Oval Bodies (DOB). Most of DOB smears express Interferon (IFN)- $\gamma$. IFN- $\gamma$ plays a role in the protection of infection while interleukin (IL)-4 in the opposite.

AIM: The purpose of this study is to determine if there is a difference between an expression of IFN- $\gamma$ and IL-4 in DOB and whether IFN- $\gamma$ is associated with the protection of the disease.

MATERIALS AND METHODS: Included in this study 41 cases of tuberculous lymphadenopathy with DOB that were not successfully treated with common antibiotics but succeeded with ATD. Antigen expression was determined using rabbit polyclonal to IFN- $\gamma$, (ab9657), and IL-4 (ab9622), Abcam. The expression was categorized as positive and negative. The details of the 41 cases were 37 cases $(90 \%)$ with IFN- $\gamma(+), 4(10 \%)$ with IFN- $\gamma(-), 10(24 \%)$ with IL-4 $(+)$, and $31(76 \%)$ with IL-4 (-). Thirty cases expressed IFN- $\gamma(+)$ and IL-4 (-), 1: IFN- $\gamma(-)$ and IL-4 (+), 8: IFN- $\gamma(+)$ and IL-4 (+), and 2: IFN- $\gamma(-)$ and IL-4 (-).

RESULTS: IFN- $\gamma$ is more frequently expressed in DOB compared to IL-4 ( $p<0.05$, the Fisher's exact tests).

CONCLUSION: IFN- $\gamma$ can be benefited as the indicator of protection to the tuberculous process.

\section{Introduction}

Tuberculosis (TB) is one of the world's most important public health problems. In 2017, TB caused an estimated 1.3 million deaths [1]. The incidence of extrapulmonary TB is on a rise over the last few years, has increased in parallel with the increase in the incidence of HIVIAIDS infection worldwide [2], [3], [4], [5]. TB can be found in almost any site in the body and it can affect organs other than the lung such as pleura, lymph nodes, abdomen, skin, joints, bones, genitourinary tract, and meninges [5].

After infection, complex interactions between the mycobacterium TB (MTB) bacilli and the human body's immune system begin with phagocytosis MTB by macrophages and activate the immune response through the release of various cytokines and chemokines secreted by different cell types such as $\mathrm{T}$ helper 1 (Th1, pro-inflammatory) and T helper 2 (Th2, anti-inflammatory) cells [6]. The theory of balance between Th1 and Th2 as a double-edged sword has been widely studied, especially the role of IFN- $\gamma$ and
Th2 cytokines. MTB is a strong induction of IFN- $\gamma$ and almost common detected in infected hosts but the presence of IL-4 varies greatly. The IL-4 cytokines play a role in regulating the development of Th1 cells and macrophage activity as well as an excessive reducer of Th1 work [7], [8], [9].

In general, IFN- $\gamma$ is considered to protect against TB, while IL-4 is associated with a lack of protection against TB [7], [10]. The increase of IFN- $\gamma$ activation ultimately leads to affect the destruction of pathogens through increased phagocytosis, pro-inflammatory responses, and lymphocyte recruitment [11]. IL-4 can be considered a potential marker for active TB [12]. The increased production of IL-4 could be detected in TB patients, especially cavitary TB. The progressive disease, reactivation of latent infection, and tissue damage are both associated with increased production of IL-4.

We noticed the cases that have been cytologically diagnosed as common chronic lymphadenitis which cannot be treated with ordinary antibiotics but have succeeded with a first-line essential anti- TB drug (ATD), although it takes longer, up to a year or more. 
Reexamining the smears, we got some cases that showed the structures that are often seen but considered meaningless, which we called Dark Oval Bodies (DOB). DOBs are small bodies of dark ovalshaped, bluish-black color contained in macrophages, in specimen stained with May Grunewald Giemsa (MGG). The smears containing DOB structure usually immunocytochemical express IFN- $\gamma$ and do not show necrotic tissue. IFN- $\gamma$ secreted by CD4 (+) T cells played a major role in the protection of infection. IL-4 is an anti-inflammatory cytokine that has a damaging effect on TB that causes deactivation of macrophages and suppresses the production of IFN- $\gamma$.

Based on this background, we want to elaborate if there is a difference between an expression of IFN- $\gamma$ and IL-4 in DOB lesions which will further determine whether expression of IFN- $\gamma$ is associated with the protection of the disease.

\section{Materials and Methods}

A cross-sectional study on 41 smears collected from June 2018 to May 2019, from the Anatomy Pathology Diagnostic Center of the Faculty of Medicine, University of North Sumatra, Medan, Indonesia. All cases were diagnosed as TB based on response to the ATD (ex juvantibus). The term ex juvantibus refers to the process of making an inference about disease causation from an observed response of the disease to treatment. The cases were initially treated with common antibiotics, however, unsuccessful, but success with anti-tuberculous drugs.

Most patients presented with swelling in the neck $(90 \%)$ and the rest were from temporal and occipital regions. $44 \%$ were adults (19-24 years) and $17 \%$ were children ( $\leq 18$ years). Sixty-three percent were female and $37 \%$ were male. In general, patients have experienced swelling of the neck on average for 3 weeks (range: 2-4 weeks). Acid-fast bacilli were not examined.

Verbal consents were produced by the participants. Ethical clearance was obtained from the Health Research Ethical Committee of the Faculty of Medicine, University of Sumatera/H. Adam Malik General Hospital.

\section{Fine-needle aspiration cytology examination}

Fine-needle aspiration was done by a pathologist using a $20-23-\mathrm{G}$ needle $(30-50 \mathrm{~mm}), 10-\mathrm{ml}$ of a disposable syringe, and a Comeco Swedia pistolet, who fixed the enlarged lymph node and inserted the needle in various directions. The specimens were immediately stained with a Diff-Quik staining protocol.

\section{Immunocytochemistry examination}

After rinsing the slides for a short time in phosphate-buffered saline (PBS), incubated the slides with hydrogen peroxide for 30 min to block endogenous peroxidase activity. After taking the microwave antigen, blocking the items with $5 \%$ normal serum horse (NHS) for $15 \mathrm{~min}$, the slides were then treated with primary antibodies - rabbit polyclonal to anti-interferon- $\gamma$ (IFN- $\gamma$, ab9657), and rabbit polyclonal to anti-interleukin-4 (IL-4, ab9622), both from Abcam, London, England, at 1/100 dilution overnight, then treated with Dako Real En Vision.

The antigen is visualized with diaminobenzidine (DAB) and anti-staining with hematoxylin.

\section{Evaluation of immunostaining}

Stained stuff was categorized as positive and negative assessment.

\section{Statistical analysis}

Fisher's exact tests were used to determine the relationship between two variables. $p<0.05$ was considered significant.

\section{Cytology}

Cytological characteristics of DOB of tuberculous lymphadenitis are observed in Figure 1.

\section{Expression of IFN- $\gamma$ and IL-4 in DOB}

Figure 2 showed the expression of IFN- $\gamma$ in most of the tuberculous lymphadenitis with DOB.

Figure 3 showed the expression of IL-4 in most of the tuberculous lymphadenitis with DOB.

The details of the 41 cases were 37 cases $(90 \%)$ with positive expressions of IFN- $\gamma$, four cases

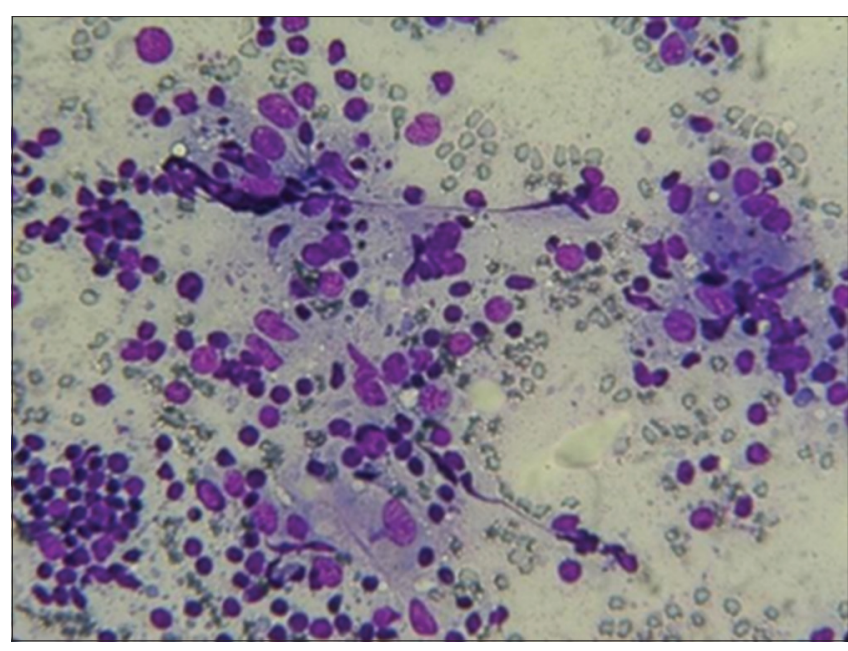

Figure 1: Aspirate of the small dark oval body inside grouped some macrophages (DOB) (MGG, ×400) 


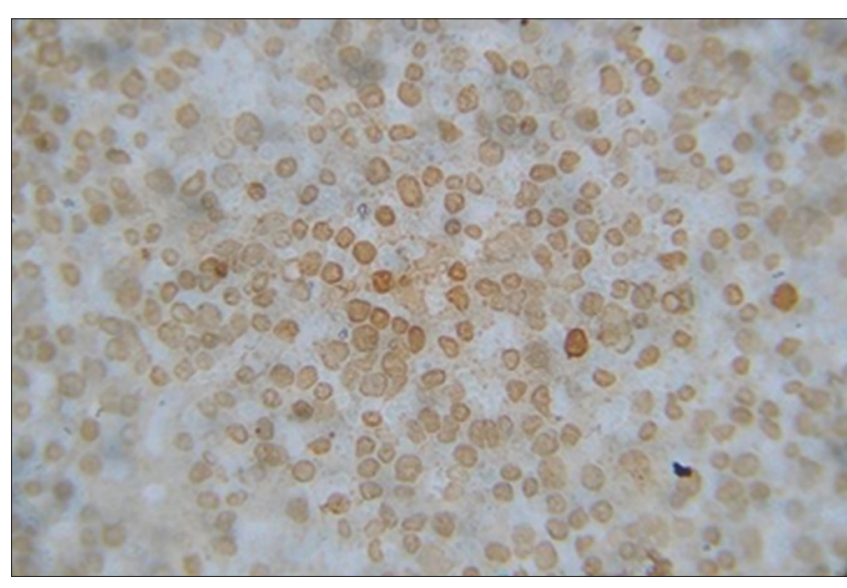

Figure 2: Positive IFN-y expression (ICC, $\times 400)$

$(10 \%)$ with negative IFN- $\gamma$, ten cases $(24 \%)$ with positive IL-4, and 31 cases (76\%) with negative IL-4. Thirty cases expressed IFN- $\gamma(+)$ and did not express IL-4 (-), one case of IFN- $\gamma(-)$ and IL-4 (+), eight cases of IFN- $\gamma(+)$ and IL-4 (+), and two cases of IFN- $\gamma(-)$ and IL-4 (-).

IFN- $\gamma$ was more frequently expressed in $\mathrm{DOB}$ lesion when compared to IL-4 $(p<0.05)$.

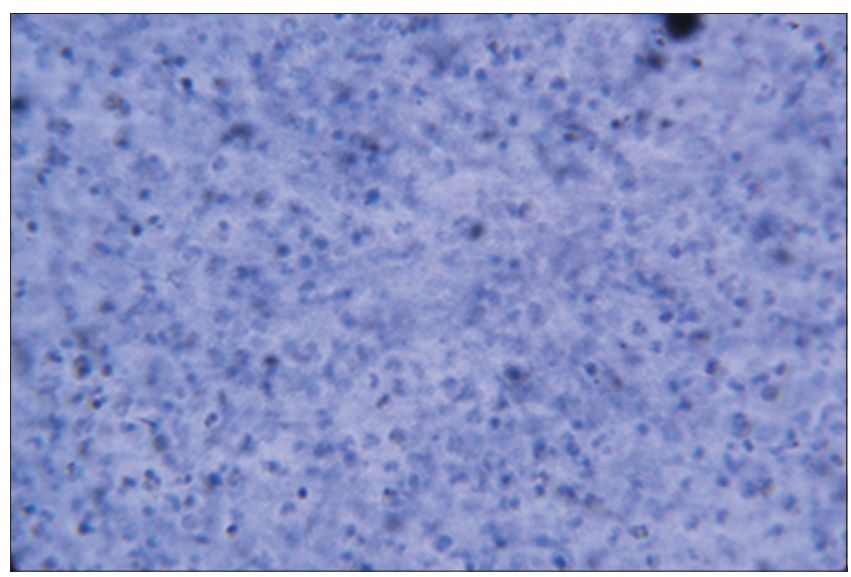

Figure 3: Negative IL-4 expression (ICC, $\times 400$ )

\section{Discussion}

In tuberculous lymphadenitis, little is known about the mechanisms whereby the human immune system controls the influence of specific cytokines. The formation of granulomas containing multinucleated giant cells is one of the hallmarks of an effective immune response against $M$. tuberculosis [2].

In our previous study on patients with $\mathrm{DOB}$ in which the aspirate was serous with or without blood, the administration of ATDs showed significant improvement [13], so we suggested that DOB was involved in the tuberculous process.

In our 41 cases of DOB, 37 (90\%) expressed IFN- $\gamma$, and $31(76 \%)$ did not IL-4. Our findings are in accordance with those of the previous studies, suggesting that IFN- $\gamma$ is required to control this infection [14]. Thus, this study confirms previous observations that patients with TB produce large amounts of IFN- $\gamma$ and low levels of IL-4 [15]. The increase of IFN- $\gamma$ could be associated with protective effects for TB. IL-4 cytokine is secreted by Th2 cells can induce anti-inflammatory effects by decreasing the activation of macrophages through the classical pathway [15]. It was reported that overexpression of IL-4 increased the severity of TB [16], [17]. In other words, if IL-4 is not expressed the severity decreases. It is in accordance with our study where IL-4 was not expressed in $31(76 \%)$ of cases.

Atypical mycobacterial TB also known as mycobacterium avium complex (MAC), nontuberculous mycobacteria (NTM), environmental mycobacteria, atypical mycobacteria, and mycobacteria other than TB (MOTT) is mycobacteria which do not cause TB or leprosy (also known as Hansen's disease). MAC do cause pulmonary diseases that resemble TB [18]. Mycobacteriosis is usually meant to exclude TB. They occur in many animals, including humans.

Treatment of atypical mycobacterial infections depends on the infecting organism and the severity of the infection. In most cases a course of antibiotics is necessary. These include rifampicin, ethambutol, isoniazid, minocycline, ciprofloxacin, clarithromycin, azithromycin, and cotrimoxazole. Usually, treatment consists of a combination of drugs.

Although lesions with $\mathrm{DOB}$ can be treated with ATD, most cases require a longer time even up to 1 year or more. We cannot elucidate why this happened. The possible explanation is that the lesions with $D O B$ are not only caused by TB but also by MAC and that MAC can also be treated with ATD even though the duration of treatment is longer. If the possibility is true, then DOB can be thought of as a cytological description of MAC. In cases of presumed tuberculous neck lymph node infections, differential diagnosis of atypical mycobacterial lymphadenitis should always be considered, because medical treatment differs fundamentally.

In summary, our data suggest that the expression of IFN- $\gamma$ in DOB may be an immune response to resolve the infection. These findings have implications in designing new immune-intervention strategies for TB by modulation of the host immune response, using IFN- $\gamma$ and anti-IL-4.

\section{Conclusion}

IFN- $\gamma$ can be benefi ted as an indicator of protection to the tuberculous process, where IFN- $\gamma$ is more frequently expressed in DOB lesion compared to IL-4. 


\section{Conflicts of interest}

The authors would like to state that this study has no conflict of interest and has followed all ethical consideration agreed by the Health Research Ethical Committee of the Faculty of Medicine, University of North Sumatera/H. Adam Malik General Hospital with No. 580/TGL /KEPK FK USU-RSUP HAM/2019.

\section{References}

1. World Health Organization. Global Tuberculosis Report. Geneva: World Health Organization; 2018.

2. Mustafa T, Stanley J, Sayoki GM. Immunohistochemica analysis of cytokines and apoptosis in tuberculous lymphadenitis. Immunology. 2006;117(4):454-62. https://doi. org/10.1111/j.1365-2567.2005.02318.x

PMid:16556259

3. Mohapatra PR, Janmeja AK. Tuberculous lymphadenitis. J Assoc Physicians India. 2009;57(8):585-90.

PMid:20209720

4. Tadele A, Beyene D, Hussein J, Gemechu T, Birhanu A, Mustafa $\mathrm{T}$, et al. Immunocytochemical detection of Mycobacterium tuberculosis complex specific antigen, MPT64, improves diagnosis of tuberculous lymphadenitis and tuberculous pleuritis. BMC Infect Dis. 2014;14:585. https://doi. org/10.1186/s12879-014-0585-1

PMid:25421972

5. Gupta V, Bhake A. Clinical and cytological features in diagnosis of peripheral tubercular lymphadenitis a hospital-based study from central India. Indian J Tuberc. 2017;64(4):309-13. https:// doi.org/10.1016/j.ijtb.2016.11.032

PMid:28941854

6. Kaufmann SH. Protection against tuberculosis: Cytokines, T cells, and macrophages. Ann Rheum Dis. 2002;61(Suppl 2):ii54-8. https://doi.org/10.1136/ard.61.suppl_2.ii54 PMid:12379623

7. Flynn JL, Chan J, Lin PL. Macrophages and control of granulomatous inflammation in tuberculosis. Mucosal Immunol. 2011;4(3):271-8. https://doi.org/10.1038/mi.2011.14 PMid:21430653

8. Romero-Adrian TB, Leal-Montiel J, Fernández G, Valecillo A. Role of cytokines and other factors involved in the Mycobacterium tuberculosis infection. World J Immunol. 2015;5(1):15-60.

\section{https://doi.org/10.5411/wji.v5.i1.16}

9. Ridha S, Fatah K, Juffrie M, Setyati A. Differences in interferon gamma in childhood tuberculosis. Sari Pediatr. 2017; 18(5):38590. https://doi.org/10.14238/sp18.5.2017.385-90

10. Al-Attiyah R, Madi NM, El-Shamy AM, Wiker HG Andersen P, Mustafa AS. Cytokine profiles in tuberculosis patients and healthy subjects in response to complex and single antigens of Mycobacterium tuberculosis. FEMS Immunol Med Microbiol. 2006;47(2):254-61. https://doi. org/10.1111/j.1574-695x.2006.00110.x

PMid:16831212

11. Kak G, Raza M, Tiwari BK. Interferon-gamma (IFN- $\gamma$ ): Exploring its implications in infectious diseases. Biomol Concepts. 2018;9(1):64-79. https://doi.org/10.1515/bmc-2018-0007 PMid:29856726

12. Koo GC, Gan $Y$. The innate interferon gamma response of $\mathrm{BALB} / \mathrm{C}$ and $\mathrm{C} 57 \mathrm{BL} / 6$ mice to in vitro Burkholderia pseudomallei infection. BMC Immunol. 2006;7:19. PMid: 16919160

13. Lubis HM. Badan-badan Kecil Berbentuk Oval Gelap di dalam Kelompokan Makrofag dan Bercak-bercak Gelap: Dua Struktur Terabaikan dalam Diagnosis Limfadenitis Tuberkulosis. Tesis. Available from: http://www.repository.usu.ac.id/ handle/123456789/26817. [Last accessed on 2020 Nov 11].

14. Naslednikova IO, Urazova OI, Voronkova OV, Strelis AK, Novitsky VV, Nikulina EL, et al. Allelic polymorphism of cytokine genes during pulmonary tuberculosis. Bull Exp Biol Med. 2009;148(2):175-80. https://doi.org/10.1007/ s10517-009-0674-0

PMid:20027321

15. Ma M, Xie L, Wu S, Tang F, Li H, Zhang Z, et al. Toll-like receptors, tumor necrosis factor- $\alpha$, and interleukin-10 gene polymorphisms in risk of pulmonary tuberculosis and disease severity. Hum Immunol. 2010;71(10):1005-10. https://doi. org/10.1016/j.humimm.2010.07.009

PMid:20650298

16. Surewicz K, Aung H, Kanost RA, Jones L, Hejal R, Toossi Z. The differential interaction of p38 MAP kinase and tumor necrosis factor- $\alpha$ in human alveolar macrophages and monocytes induced by Mycobacterium tuberculois. Cell Immunol. 2004;228(1):3441. https://doi.org/10.1016/j.cellimm.2004.03.007 PMid: 15203318

17. Wu S, Wang Y, Zhang M, Wang M, He JQ. Genetic variants in IFNG and IFNGR1 and tuberculosis susceptibility. Cytokine. 2019;123:154775. https://doi.org/10.1016/j.cyto.2019.154775 PMid:31310896

18. Dünne AA, Kim-Berger HS, Zimmermann S, Moll R, Lippert BM Atypical Mycobacterial tuberculosis a diagnostic and therapeutic dilemma? Case reports and review of the literature. Otolaryngol Pol. 2003;57(1):17-23.

PMid:12741139 